\title{
Upregulation of microRNA-31 is associated with poor prognosis in patients with advanced colorectal cancer
}

\author{
NOBUHITO KUBOTA ${ }^{1}$, FUMITAKA TANIGUCHI ${ }^{1}$, AKIHIRO NYUYA ${ }^{2}$, \\ YUZO UMEDA $^{1}$, YOSHIKO MORI ${ }^{1}$, TOSHIYOSHI FUJIWARA ${ }^{1}$, HIROAKI TANIOKA ${ }^{2}$, \\ ATSUSHI TSURUTA ${ }^{3}$, YOSHIYUKI YAMAGUCHI ${ }^{2}$ and TAKESHI NAGASAKA ${ }^{2}$ \\ ${ }^{1}$ Department of Gastroenterological Surgery, Okayama University Graduate School of Medicine, Dentistry and \\ Pharmaceutical Sciences, Okayama 700-8558; Departments of ${ }^{2}$ Clinical Oncology and ${ }^{3}$ Digestive Surgery, \\ Kawasaki Medical School, Kurashiki, Okayama 701-0192, Japan
}

Received July 8, 2019; Accepted November 14, 2019

DOI: $10.3892 / 01.2020 .11365$

\begin{abstract}
Colorectal cancer (CRC) manifests after the accumulation of genetic and epigenetic alterations along with tumor microenvironments. MicroRNA (miRNA/miR) molecules have been revealed to serve in critical roles in the progression various types of cancer, and their expression level is often an important diagnostic, predictive or prognostic biomarker. The aim of the present study was to evaluate the potential of miRNAs as prognostic biomarkers for patients with advanced CRC. miRNA arrays were performed on CRC specimens obtained from tumors with various molecular statuses [e.g. KRAS proto-oncogene, GTPase $(K R A S) / \mathrm{B}-\mathrm{Raf}$ proto-oncogene, serine/threonine kinase $(B R A F) /$ microsatellite instability (MSI)], and their paired normal mucosal specimens. The miRNA array revealed that miR-31-5p $(m i R-31)$ was specifically upregulated in CRCs with the $B R A F$ V600E mutation, the results of which were supported by subsequent analysis of a dataset retrieved from The Cancer Genome Atlas (TCGA) database, which contained information regarding 170 patients with CRC including $51 B R A F$-mutant CRCs. Of our cohort of 67 patients with stage IV CRC, 15 (22\%) and 4 (6\%) showed KRAS and BRAF
\end{abstract}

Correspondence to: Dr Takeshi Nagasaka, Department of Clinical Oncology, Kawasaki Medical School, 577 Matsushima, Kurashiki, Okayama 701-0192, Japan

E-mail: takeshin@med.kawasaki-m.ac.jp

Abbreviations: CRC, colorectal cancer; CI, confidence interval; $\Delta \mathrm{Ct}, \Delta$ threshold cycle; EMT, epithelial-mesenchymal transition; $\mathrm{HR}$, hazard ratio; MSI, microsatellite instability; miRNA/miR, microRNA; MST, median survival time; OS, overall survival; RT-qPCR, reverse transcription-quantitative PCR; RASA1, RAS p21 GTPase-activating protein 1; RQ, expression relative quotient; SATB2, special AT-rich sequence-binding protein 2; TCGA, The Cancer Genome Atlas

Key words: colorectal cancer, microRNA, microRNA-31, BRAF, prognostic biomarker
V600E mutations, respectively. Since the median $m i R-31$ expression was 3.45 (range, 0.004-6330.531), the cut-off value was chosen as 3.5 , and all tumors were categorized into two groups accordingly (high-/low-miR-31 expression). The high $m i R-31$ expression group $(\mathrm{n}=33)$ was significantly associated with a poorer mortality (univariate hazard ratio $=2.12 ; 95 \%$ confidence interval, 0.23-0.95; $\mathrm{P}=0.03$ ) and exhibited a shorter median survival time (MST; 20.1 months) compared with the low miR-31 expression group $(\mathrm{n}=34)$ (MST, 38.3 months; $\mathrm{P}=0.03$ ), indicating that $m i R-31$ is a promising prognostic biomarker for patients with advanced CRC. Thus, performing a functional analysis of $m i R-31$ expression may lead to the development of new targeted therapies for the various genetic subtypes of CRC.

\section{Introduction}

Colorectal cancer (CRC) is the third most common cancer type and is a leading cause of cancer-associated mortality worldwide $(1,2)$. A certain subset of CRC arises from the sequential accumulation of genetic and epigenetic alterations. microRNAs (miRNA/miR) have been revealed as candidates in tumor progression in various cancer types, and changes in their expression levels are consequently being investigated with the purpose of identifying clinical biomarkers (3-9). miRNAs constitute a class of small, non-coding RNA molecules, 18-27 nucleotides in length that function as post-transcriptional regulators of gene expression, either serving as oncogenes or tumor suppressor genes $(10,11)$. In CRC, several miRNAs are aberrantly expressed and target genes downstream of epidermal growth factor receptor (EGFR) signaling; for example, $m i R-143$ and -145 target KRAS and BRAF proteins, respectively (12). Nosho et al (13) revealed that high $m i R-31-5 p$ ( $m i R-31)$ expression [miR-31 has the two subtypes; miR-31 (hsa-mir-31-5p) and $m i R-31 *$ (hsa-mir-31-3p)] was significantly associated with $B R A F$ V600E mutation $(\mathrm{P}<0.0001)$ and a poorer prognosis in a large statistical population of 721 patients with CRC. Additionally, downregulation of BRAF protein expression, following transfection of an $m i R-31$ inhibitor into CRC cells was demonstrated (13). Thus, the aforementioned evidence indicates that $m i R-31$ may regulate the activation of BRAF 
protein in CRC, and may also serve an important role in the downstream EGFR signaling pathway.

The present study investigated $m i R-31$ that is significantly associated with advanced CRC with $B R A F$ V600E mutation, as the presence of $B R A F$ mutations is known to be a poor prognostic factor in CRC (14-18). According to the results of the microarray analysis, it was revealed that $m i R$ - 31 expression is upregulated in $B R A F$-mutant tumors. Therefore, the association between $m i R-31$ expression levels and $B R A F$-mutant CRCs was further investigated using a dataset retrieved from The Cancer Genome Atlas (TCGA) database. Finally, $m i R-31$ expression patterns observed in CRC were further supported by investigating the $m i R-31$ expression level in patients with stage IV CRC.

\section{Materials and methods}

Patients. From a cohort of 598 patients with CRC, 129 patients with stage IV CRC underwent primary tumor resection before other treatments, such as chemotherapy, radiotherapy or chemoradiotherapy, at Okayama University Hospital (Okayama, Japan) between March 2003 and May 2013. Of these, only 67 patients were evaluated and analyzed in the present study due to availability of both tumors and the paired normal mucosa (Fig. 1). The tumors and the corresponding normal mucosa were stored at $-80^{\circ} \mathrm{C}$ following preservation with RNAlater $^{\circledR}$ (Sigma-Aldrich; Merck KGaA). Clinical, pathological and survival data were extracted from medical records. The pathological stage was determined according to the International Union Against Cancer TNM staging system (seventh edition) (19). Institutional review board approval was granted by the Ethics Committee of Okayama University, and written informed consent was provided from all patients for the use of their tissues and clinical data.

DNA and RNA extraction. DNA was extracted from 67 fresh-frozen paired tumor and healthy colonic mucosal tissue specimens, which were obtained from a site adjacent to the primary tumor, $>10 \mathrm{~cm}$ from the tumor border. DNA from the fresh-frozen tissue specimens was extracted using a QIAamp DNA Mini kit (Qiagen, Inc.) according to the manufacturer's protocol. Total miRNA was isolated from frozen tissue specimens preserved by RNAlater ${ }^{\circledR}$ (Sigma-Aldrich; Merck KGaA) using a miRNeasy Mini kit (Qiagen, Inc.) and quality and quantity were confirmed using a Qubit fluorometer (Qubit 2.0 or 3.0; Invitrogen; Thermo Fisher Scientific, Inc.).

BRAF and KRAS mutation analyses. A BRAF mutation in codon 600 and KRAS mutations in codons 12 and 13 were analyzed by direct sequencing using purified DNA from fresh-frozen tissues of each patient. The specific primer sequences and PCR conditions have been described previously (20). The PCR products were purified using a QIAquick PCR purification kit (Qiagen, Inc.) according to the manufacturer's protocol and were directly sequenced on an ABI 310R Genetic Analyzer (Thermo Fisher Scientific, Inc.).

Microsatellite instability (MSI) analysis. A multiplex PCR method for the detection of tumors with MSI was performed to determine the MSI status of all CRC tissues using four mononucleotide repeat markers (BAT26, NR21, NR27 and CAT25) as described previously $(21,22)$. Tumors exhibiting MSI in $\geq 1$ mononucleotide repeat marker were classified as MSI phenotype, whereas those without MSI were classified as non-MSI phenotype.

Analysis of miRNA expression in paired primary tumor and normal colonic tissue samples using miRNA microarray. Total miRNA was isolated from frozen tissue specimens using a miRNeasy Mini kit (Qiagen, Inc.) and analyzed on an Agilent 2100 Bioanalyzer (Agilent Technologies, Inc.) according to the manufacturer's protocol. SurePrint G3 Human miRNA 8x60K Rel.16.0 (Agilent Technologies, Inc.) was used to analyze miRNA expression in paired primary tumor and normal colonic tissue samples. The expression level of each probe was calculated as the sum of 20 spots of raw intensity with the background subtracted. Target miRNAs that were not detected in any spots were defined as 'undetected' and allocated an expression level of ' 0.1 '. The data were normalized to the 90 th percentile, and target miRNAs that were not detected in all the samples were excluded (9).

Preliminary analysis of the association between miR-31 expression and BRAF mutation using TCGA database. Freely available datasets regarding miRNA expression and somatic mutations of colon adenocarcinoma samples were retrieved from TCGA (23). From TCGA database (v1.0), a total of 187 CRC samples had data available regarding $m i R-31$ expression, among which the $B R A F$ mutation profile was available in 170 CRCs on the GDC Data Portal (https://portal.gdc.cancer.gov/). Thus, $m i R-31$ expression in 170 CRC tissues was subsequently analyzed. Of these, $51 \mathrm{CRCs}$ were categorized as having $B R A F$ V600E mutation (30\%).

Reverse transcription-quantitative $(R T-q) P C R$. Total miRNA was isolated from frozen tissue specimens using a miRNeasy Mini kit (Qiagen, Inc.). The expression levels of $m i R-31$ (Hs_miR-31_1 miScript Primer Assay; Qiagen, Inc.) and RNU6B (Hs_RNU6-2_1 miScript Primer Assay; Qiagen, Inc.) were analyzed using miScript primer assays. The cDNA was generated by a miScript II RT Kit (Qiagen, Inc.). RT-qPCR was performed with the gene-specific primers and a miScript SYBR $^{\circledR}$ Green PCR kit (Qiagen, Inc.) using a LightCycler 480 (Roche Diagnostics), according to the manufacturer's protocol. Briefly, reactions were incubated in a 96 -well plate at $95^{\circ} \mathrm{C}$ for $15 \mathrm{~min}$, followed by 40 cycles of $95^{\circ} \mathrm{C}$ for $15 \mathrm{sec}, 55^{\circ} \mathrm{C}$ for $30 \mathrm{sec}$ and $70^{\circ} \mathrm{C}$ for $30 \mathrm{sec}$, according to the manufacturer's protocol. The quantitative value of miRNA in a given sample was calculated by subtracting that value from the $\mathrm{Cq}$ value of $R N U 6 B$, which served as the internal reference gene. $\mathrm{Cq}$ values from duplicate reactions were averaged, and the threshold cycle value $(\Delta \mathrm{Cq})$ was calculated by subtracting the $\mathrm{Cq}$ of the $R N U 6 B$ from the $\mathrm{Cq}$ of the target $m i R-31$. The $\Delta \Delta \mathrm{Cq}$ value of tumor was calculated by subtracting the $\Delta \mathrm{Cq}$ value of the normal counterpart sample (24). The value of $2^{-\Delta \Delta C q}$ represents the expression relative quotient (RQ) of $m i R-31$. Here, the $m i R-31$ expression level (RQ of $m i R-31$ ) was presented as the ratio of the $m i R-31$ expression in cancerous tissue vs. adjacent non-cancerous tissue. A $m i R$-31 expression level $<1$ indicated that the expression levels in cancerous tissue were 


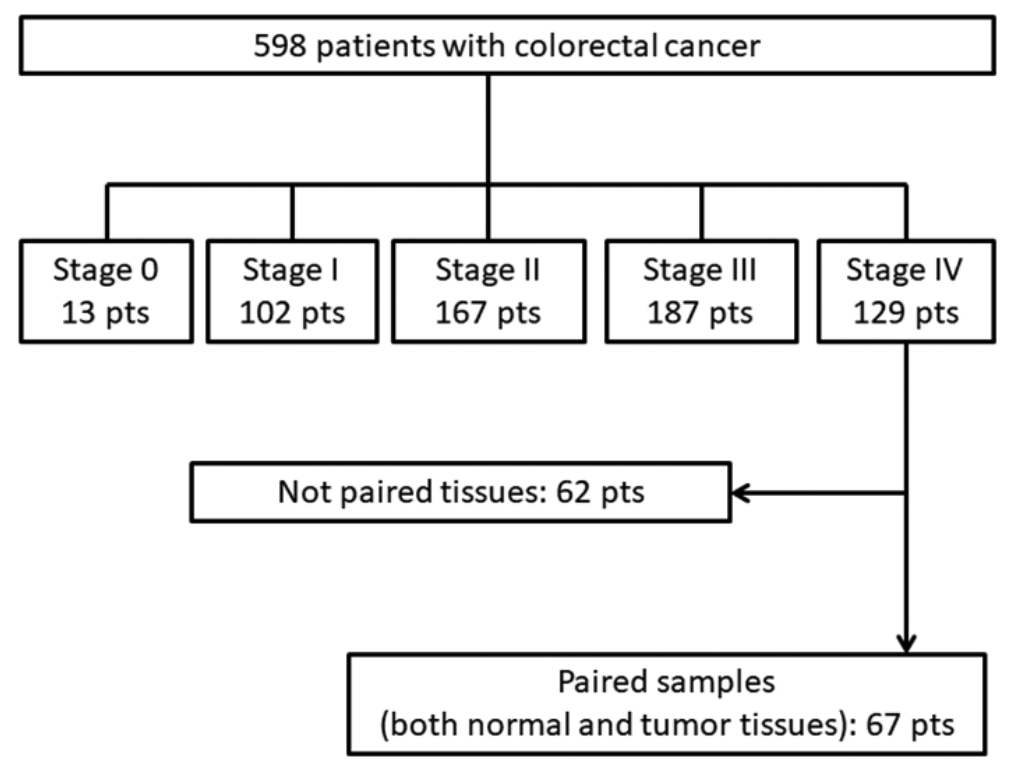

Figure 1. Strengthening the Reporting of Observational Studies in Epidemiology (STROBE) diagram of the patient cohort.

lower compared with that in the paired normal colonic tissue. Conversely, an $m i R-31$ expression level $>1$ indicated higher expression in cancerous tissue compared with that in the paired normal colonic tissue.

Statistical analysis. Statistical analyses were performed using JMP Pro software (version 14.2; SAS Institute Inc.). The miRNA expression level is presented as the mean RQ, and was measured three times in all samples. Categorical variables were compared using a $\chi^{2}$ test. $m i R$ - 31 expression levels in $B R A F$-mutant CRC tissues from TCGA were compared with those in $B R A F$-wild type CRC tissues using Dunnett's Method. Disease-specific overall survival time (OS) was calculated from the date of initial treatment to the date of death due to primary colon cancer or last follow-up for censored patients (the patients were followed up every month for stage IV cases). Survival data, $<120$ months, following initial treatment was used. Survival-based outcomes were analyzed by the Kaplan-Meier method, expressed as medians and compared with log-rank test. Univariate and multivariate analyses were performed using the Cox-proportional hazards model. The hazard ratio (HR) and $95 \%$ confidence interval (CI) were calculated from the model, and the significance of the parameters was evaluated using Wald's test. All reported P-values were from two-sided tests, and $\mathrm{P}<0.05$ was considered to indicate a statistically significant difference.

\section{Results}

Identification of miRNAs associated with CRCs expressing the $B R A F$ V600E mutation. Prior to analyzing the miRNA microarray data, six independent CRC specimens were evaluated according to their $K R A S / B R A F$ mutational profiles and MSI status, which resulted in six subtypes with different genetic and clinical features (25). No MSI tumors were observed to exhibit a $K R A S$-mutation. Therefore, the following specimens were collected: An MSI with BRAF V600E mutation, two non-MSI tumors without either KRAS or BRAF mutation (wild-type), a
non-MSI tumor with $B R A F$ V600E mutation, and two non-MSI tumor with KRAS mutation, each located in the right or left side of the colon. The two normal colonic (right colon and rectum) mucosa specimens were used as controls (Fig. 2A and Table SI). The miRNA array provided the expression status of a total of 1,368 miRNAs.

To identify miRNAs that were significantly associated with non-MSI tumors containing the BRAF V600E mutation, miRNAs exhibiting no expression among the six CRC tissues and the two corresponding normal colorectal mucosae (803 miRNAs), and miRNAs that were expressed in all the tissues (286 miRNAs), were excluded. The cluster analysis revealed that only $m i R$-31 was significantly upregulated in non-MSI CRC specimens with the BRAF V600E mutation (sample ID, 341), while $m i R-429,-375,-200 a,-200 b$ and -192 were downregulated compared with that in the other CRC phenotypes, such as CRCs with wild-type $B R A F$. Generally, molecules that are significantly and specifically upregulated in tumors are useful for screening those tumors via liquid biopsy or other screening tools (26). Therefore, subsequent analyses focused on $m i R-31$ as a candidate prognostic biomarker in the present study.

Association between miR-31 expression and BRAF-mutant $C R C$ in TCGA database. To confirm whether elevated miR-31 expression is common in $B R A F$-mutant CRC, miRNA expression and somatic mutations data from colon adenocarcinoma samples retrieved from TCGA were analyzed (Fig. 2B). From the database, a cohort of 170 patients with CRC were available for analysis of $m i R-31$ expression with respect to $B R A F$ mutation status. Among the $170 \mathrm{CRCs}$, the value of $m i R-31$ expression ranged from 0 to 447.6 (median, 6.27). BRAF mutation was observed in 51 patients with CRC (30\%), and all 51 showed higher $m i R-31$ expression (median value, 45.47; 95\% CI, 20.59-70.35) compared to patients with CRC expressing wild-type $B R A F$ (median value, 21.57; 95\% CI, 13.09-30.05; $\mathrm{P}=0.0228$ ).

Calculation of miR-31 expression in stage IV CRC specimens. To examine at what point during CRC progression do $m i R-31$ 
Table I. Clinicopathological features of 67 patients with stage IV CRC stratified by miR-31 expression level.

\begin{tabular}{|c|c|c|c|c|}
\hline \multirow[b]{2}{*}{ Variables } & \multirow[b]{2}{*}{ Total, $\mathrm{n}(\%)(\mathrm{n}=67)$} & \multicolumn{2}{|c|}{$m i R-31$ expression level, $\mathrm{n}(\%)$} & \multirow[b]{2}{*}{$\mathrm{P}$-value } \\
\hline & & $\begin{array}{c}\text { Low }(<3.5) \\
\quad(n=34)\end{array}$ & $\begin{array}{l}\text { High }(>3.5) \\
\quad(n=33)\end{array}$ & \\
\hline \multicolumn{5}{|l|}{ Age, years } \\
\hline Mean (range) & $64.1(35-85)$ & $62.9(41-85)$ & $65.3(35-82)$ & \\
\hline$<65$ & $28(41.8)$ & $17(50.0)$ & $11(33.3)$ & 0.218 \\
\hline$\geq 65$ & $39(58.2)$ & $17(50.0)$ & $22(66.7)$ & \\
\hline Gender & & & & 0.621 \\
\hline Female & $26(38.8)$ & $12(35.3)$ & $14(42.4)$ & \\
\hline Male & $41(61.2)$ & $22(64.7)$ & $19(57.6)$ & \\
\hline Serum CEA level, ng/ $/ \mu 1$ & & & & 0.262 \\
\hline$<5.0$ & $17(25.4)$ & $11(32.4)$ & $6(18.2)$ & \\
\hline$\geq 5.0$ & $50(74.6)$ & $23(67.6)$ & $27(81.8)$ & \\
\hline Tumor location & & & & 0.392 \\
\hline Right & $15(22.4)$ & $6(17.6)$ & $9(27.3)$ & \\
\hline Left & $52(77.6)$ & $28(82.4)$ & $24(72.7)$ & \\
\hline Histology & & & & 0.186 \\
\hline Well or moderate & $57(85.1)$ & $31(91.2)$ & $26(78.8)$ & \\
\hline Poor or mucinous & $10(14.9)$ & $3(8.8)$ & $7(21.2)$ & \\
\hline No. of distant metastatic sites & & & & 0.194 \\
\hline Single & $46(68.7)$ & $26(76.5)$ & $20(60.6)$ & \\
\hline Multiple & $21(31.3)$ & $8(23.5)$ & $13(39.4)$ & \\
\hline $\mathrm{T}$ factor & & & & 0.2 \\
\hline 1 & $1(1.5)$ & $0(0.0)$ & $1(3.0)$ & \\
\hline 2 & $4(6.0)$ & $3(8.8)$ & $1(3.0)$ & \\
\hline 3 & $38(56.7)$ & $22(64.7)$ & $16(48.5)$ & \\
\hline $4 a$ & $15(22.4)$ & $7(20.6)$ & $8(24.2)$ & \\
\hline $4 b$ & $9(13.4)$ & $2(5.9)$ & $7(21.2)$ & \\
\hline $\mathrm{N}$ factor & & & & 0.437 \\
\hline 0 & $13(19.4)$ & $9(26.5)$ & $4(13.3)$ & \\
\hline $1 \mathrm{a}$ & $11(16.4)$ & $5(14.7)$ & $6(18.2)$ & \\
\hline $1 b$ & $14(20.9)$ & $6(17.6)$ & $8(24.2)$ & \\
\hline $1 \mathrm{c}$ & $1(1.5)$ & $1(2.9)$ & $0(0.0)$ & \\
\hline $2 \mathrm{a}$ & $13(19.4)$ & $4(11.8)$ & $9(27.3)$ & \\
\hline $2 b$ & $12(17.9)$ & $7(20.6)$ & $5(15.2)$ & \\
\hline $\mathrm{X}$ & $3(4.5)$ & $2(5.9)$ & $1(3.0)$ & \\
\hline $\mathrm{M}$ factor & & & & 0.447 \\
\hline $1 \mathrm{a}$ & $44(65.7)$ & $24(54.5)$ & $20(45.5)$ & \\
\hline $1 b$ & $23(34.3)$ & $10(43.5)$ & $13(56.5)$ & \\
\hline MSI status & & & & Not calculated \\
\hline MSI & $0(0.0)$ & $0(0.0)$ & $0(0.0)$ & \\
\hline Non-MSI & $67(100.0)$ & $34(100)$ & $33(100)$ & \\
\hline$K R A S / R A F$ mutation status & & & & 0.0608 \\
\hline$K R A S$ mutation & $15(22.4)$ & $10(29.4)$ & $5(15.2)$ & \\
\hline$B R A F$ mutation & $4(6.0)$ & $0(0)$ & $4(12.1)$ & \\
\hline Wild-type & $48(71.6)$ & $24(70.6)$ & $24(72.7)$ & \\
\hline
\end{tabular}

P-values were calculated using $\chi^{2}$ test. miR, microRNA; $K R A S$, KRAS proto-oncogene, GTPase; $B R A F$, B-Raf proto-oncogene, serine/threonine kinase; MSI, microsatellite instability. T, N and M factor denotes the depth of invasion, the regional lymph node metastasis and the presence or otherwise of distant metastasis defied by the AJCC cancer staging (19). X denotes unclassified of $\mathrm{N}$ factor. 
Table II. Cox regression analyses of 67 patients with stage IV colorectal cancer.

\begin{tabular}{|c|c|c|c|c|}
\hline \multirow[b]{2}{*}{ Variables } & \multicolumn{2}{|c|}{ Univariate } & \multicolumn{2}{|c|}{ Multivariate } \\
\hline & $\mathrm{HR}(95 \% \mathrm{CI})$ & P-value & $\mathrm{HR}(95 \% \mathrm{CI})$ & P-value \\
\hline \multicolumn{5}{|l|}{ Age, years } \\
\hline$>65$ vs. $<65$ & $1.78(0.86-3.69)$ & 0.1197 & $1.41(0.61-3.26)$ & 0.4244 \\
\hline \multicolumn{5}{|l|}{ Sex } \\
\hline Female vs. male & $1.19(0.59-2.43)$ & 0.6249 & $1.18(0.52-2.69)$ & 0.6891 \\
\hline \multicolumn{5}{|l|}{ Serum CEA level, $\mathrm{ng} / \mu \mathrm{l}$} \\
\hline$>5$ vs. $<5$ & $1.24(0.55-2.78)$ & 0.5999 & $1.23(0.53-2.87)$ & 0.6243 \\
\hline \multicolumn{5}{|l|}{ Tumor location } \\
\hline Right vs. left & $1.10(0.47-2.55)$ & 0.8252 & $0.34(0.08-1.42)$ & 0.1394 \\
\hline \multicolumn{5}{|l|}{ Histology } \\
\hline Poor or mucinous vs. well or moderate & $3.16(1.33-7.52)$ & $0.0094^{\mathrm{a}}$ & $1.83(0.59-5.67)$ & 0.2941 \\
\hline \multicolumn{5}{|l|}{ No. of distant metastatic sites } \\
\hline Multiple vs. single & $2.95(1.46-5.96)$ & $0.0027^{\mathrm{a}}$ & $2.84(1.31-6.17)$ & $0.0083^{\mathrm{a}}$ \\
\hline \multicolumn{5}{|l|}{$K R A S / B R A F$ mutation status } \\
\hline$B R A F$ mutation vs. $K R A S$ mutation & $12.73(2.68-60.37)$ & $0.0014^{\mathrm{a}}$ & $13.18(2.11-82.39)$ & $0.0058^{\mathrm{a}}$ \\
\hline$K R A S$ mutation vs. wild-type & $1.11(0.47-2.58)$ & 0.8152 & $2.20(0.73-6.64)$ & 0.1611 \\
\hline$B R A F$ mutation vs. wild-type & $14.08(3.37-58.85)$ & $0.0003^{b}$ & $29.03(3.58-235.29)$ & $0.0016^{\mathrm{a}}$ \\
\hline \multicolumn{5}{|l|}{$m i R-31$ expression level } \\
\hline High vs. low & $2.12(1.05-4.29)$ & $0.0356^{\mathrm{a}}$ & $1.48(0.67-3.29)$ & 0.3358 \\
\hline
\end{tabular}

${ }^{\mathrm{a}} \mathrm{P}<0.05 .{ }^{\mathrm{b}} \mathrm{P}<0.001$. miR, microRNA; HR, hazard ratio; $\mathrm{CI}$, confidence interval; miR, microRNA; KRAS, KRAS proto-oncogene, GTPase; $B R A F, \mathrm{~B}-\mathrm{Raf}$ proto-oncogene, serine/threonine kinase; MSI, microsatellite instability.

expression levels affect clinical outcomes in advanced CRC, a cohort of 67 patients with stage IV CRCs (out of a total of 598), had both frozen tumor and adjacent normal mucosa tissues available for RNA extraction, were selected (Fig. 1). Of the 67 stage IV CRC specimens, all of them were non-MSI. The median miR-31 expression level was 3.45 (mean, 142; range, 0.004-6330.531). Therefore, a cut-off value of 3.5 was used. Cases showing an $m i R-31$ expression level $\geq 3.5$ were included in the $m i R-31$ high-expression group, while cases with an $m i R-31$ expression level $<3.5$ were categorized as low expression. According to this classification, 33 and 34 cases were defined as $m i R-31$ high expression and $m i R-31$ low expression, respectively. Table I displays the clinicopathological features of patients with stage IV CRCs as classified by $m i R-31$ expression level. Of the 67 stage IV CRCs, only four had a $B R A F$ mutation and were all included in the $m i R-31$ high expression group; however, the association was not significant. Additionally, there were no significant differences in clinicopathological characteristics between the two groups.

Clinical outcomes are associated with miR-31 expression status in patients with stage IV CRCs. Among the cohort of 67 patients with stage IV CRCs, the median survival time (MST) was 29 months (95\% CI, 19.5-38 months; Fig. 3A). Stratification of patients according to their $B R A F / K R A S$ mutation status was then conducted; the MST of patients with $B R A F$-mutant, KRAS-mutant and wild-type CRC was 1.8, 29 and 30 months, respectively (Fig. 3B; P<0.0001). Next, clinical outcomes were analyzed with respect to $m i R-31$ expression status. The MST of the $m i R-31$ high expression group was 20 months, while that of the miR-31 low expression group was 38 months (Fig. 4A; $\mathrm{P}=0.0314)$. Of note, the four patients with $B R A F$-mutant CRCs (MST, 1.8 months) were all in the $m i R-31$ high-expression group, and the prognosis of the miR-31 high-expression group may have been affected by this subgroup of patients. Therefore, during subsequent prognostic analysis patients with $B R A F$-mutant CRC were excluded. The miR-31 high expression group still maintained a tendency toward poor prognosis compared with the $m i R-31$ low-expression group, although it did not reach statistical significance (Fig. 4B).

Finally, univariate and multivariate analyses were conducted using the Cox-proportional hazards model to determine the factors that influenced poorer outcomes in patients with stage IV CRC (Table II). The univariate analysis revealed that tumors with poor or mucinous histology, multiple distant metastatic sites, the BRAF V600E mutation and higher $m i R-31$ expression levels statistically exhibited a poorer prognosis; however, in the multivariate analysis, only multiple distant metastatic sites and the presence of the BRAF V600E mutation, indicated a poorer prognosis.

\section{Discussion}

In the present study, the potential of $m i R-31$ as a prognostic biomarker for patients with advanced CRC was demonstrated, particularly in patients with stage IV of the disease. $m i R-31$ is 
A
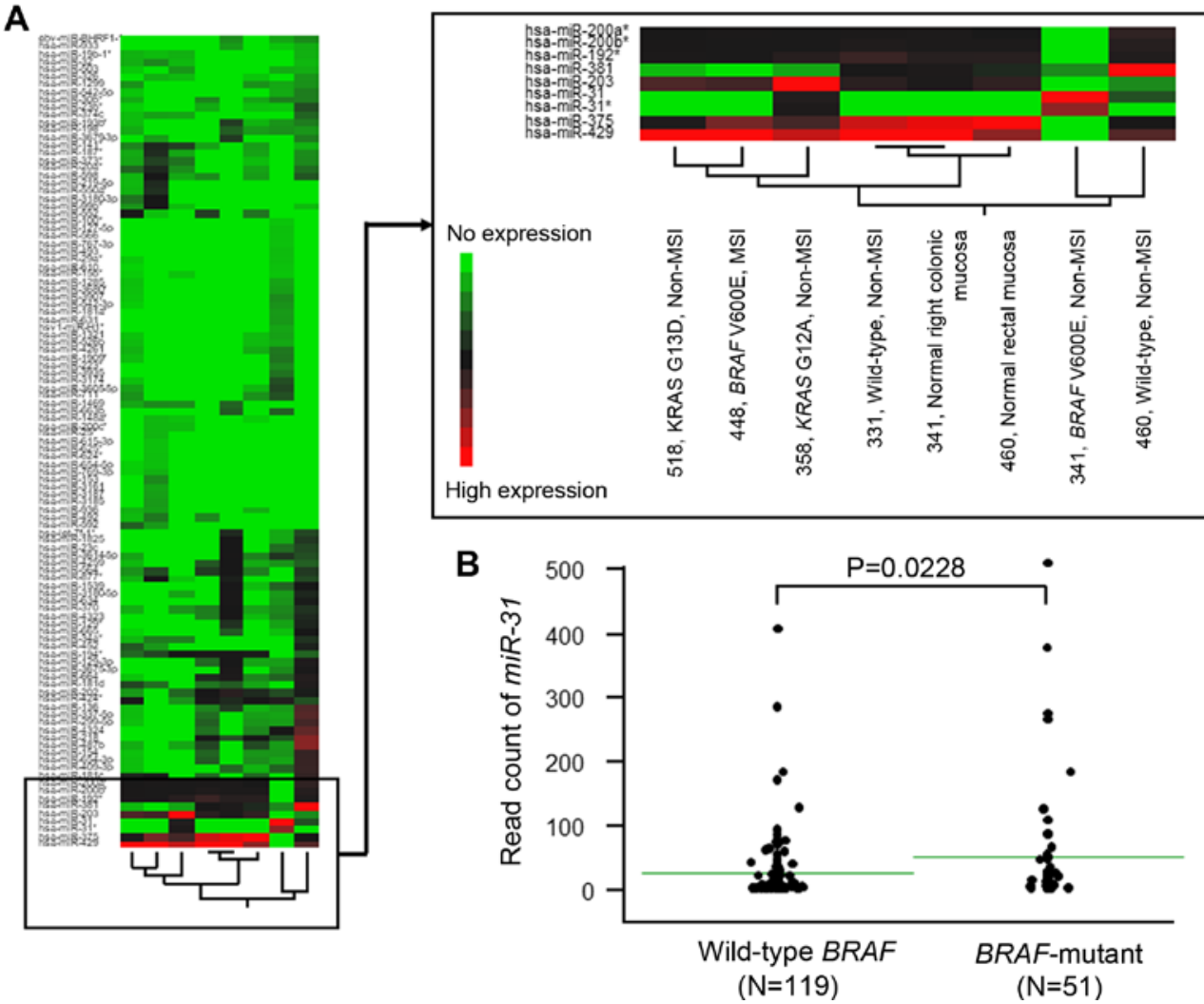

Figure 2. Association between CRC with a $B R A F$ mutation and $m i R-31$ expression status. (A) Cluster analysis of the miRNA microarray. $m i R-31$ is highly expressed in CRC tissues with a BRAF mutation (particularly those without MSI), compared with CRC tissues without $B R A F$ mutation. (B) The read count of $m i R-31$ was compared between CRCs with mutant and wild-type BRAF from The Cancer Genome Atlas database. The bar denotes the mean read count of $m i R$-31. miR, microRNA; KRAS, KRAS proto-oncogene, GTPase; $B R A F$, B-Raf proto-oncogene, serine/threonine kinase; MSI, microsatellite instability; CRC, colorectal cancer.
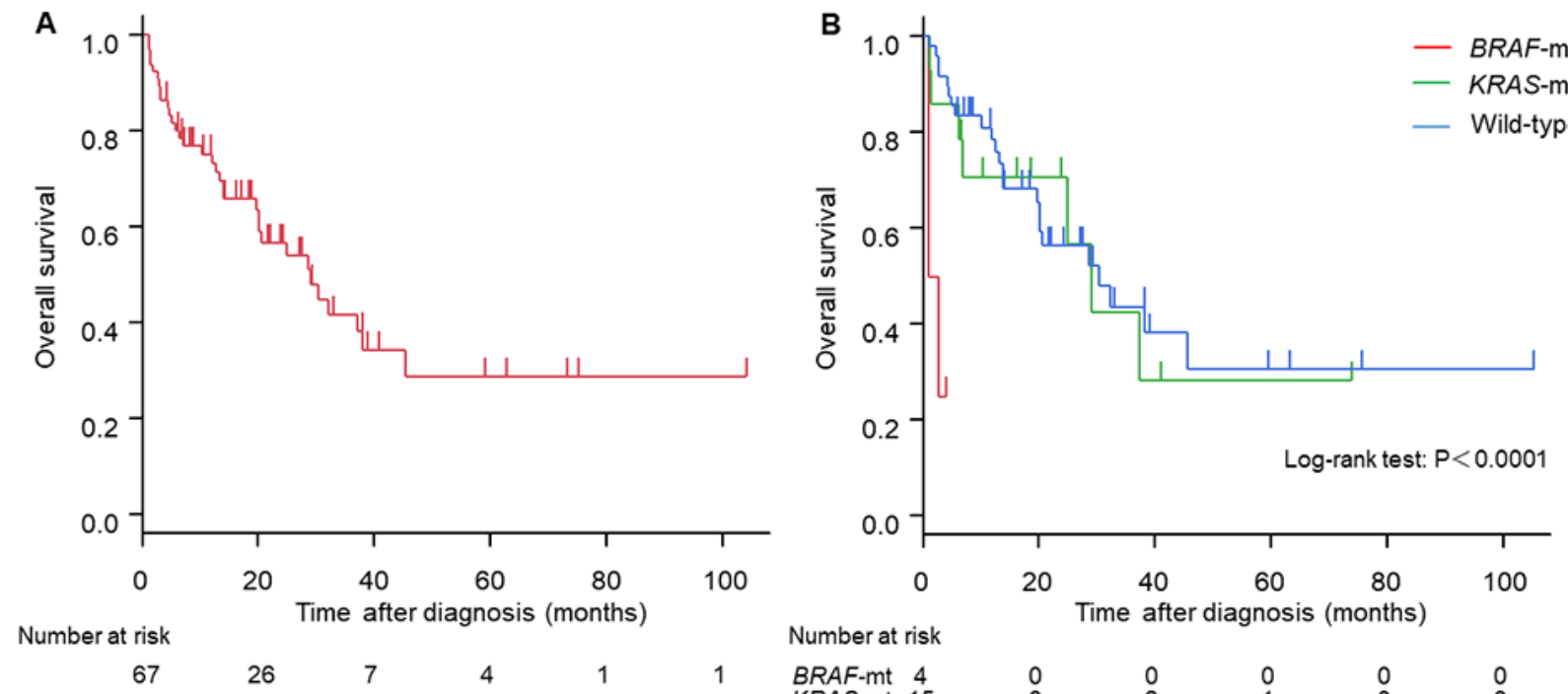

Number at risk

$\begin{array}{lcccccc}\text { BRAF-mt } & 4 & 0 & 0 & 0 & 0 & 0 \\ \text { KRAS-mt } & 15 & 6 & 2 & 1 & 0 & 0 \\ \text { Wild/Wild } & 48 & 20 & 5 & 3 & 1 & 1\end{array}$

Figure 3. Kaplan-Meier curves for patients with stage IV colorectal cancer. (A) Overall survival of a cohort of 67 patients. (B) Overall survival with respect to the KRAS/BRAF mutational spectrum. KRAS, KRAS proto-oncogene, GTPase; BRAF, B-Raf proto-oncogene, serine/threonine kinase; mt, mutant.

located on chromosome 9p21.3 and is reportedly deregulated in various types of human cancer, for example, esophageal, breast, ovarian and gastric cancers (3,27-30). Moreover, in $\mathrm{CRC}$, an association has been reported between upregulation of $m i R-31$ and poor tumor differentiation (13), oncogenic potential (13,31-34), deeper invasion $(34,35)$ and advanced disease stages $(31,34,35)$.

In the advanced stages of $C R C$, the presence of $B R A F$ mutations is demonstrated to be a poor prognostic factor (14-18), so specific miRNAs that are significantly associated with $B R A F$ 

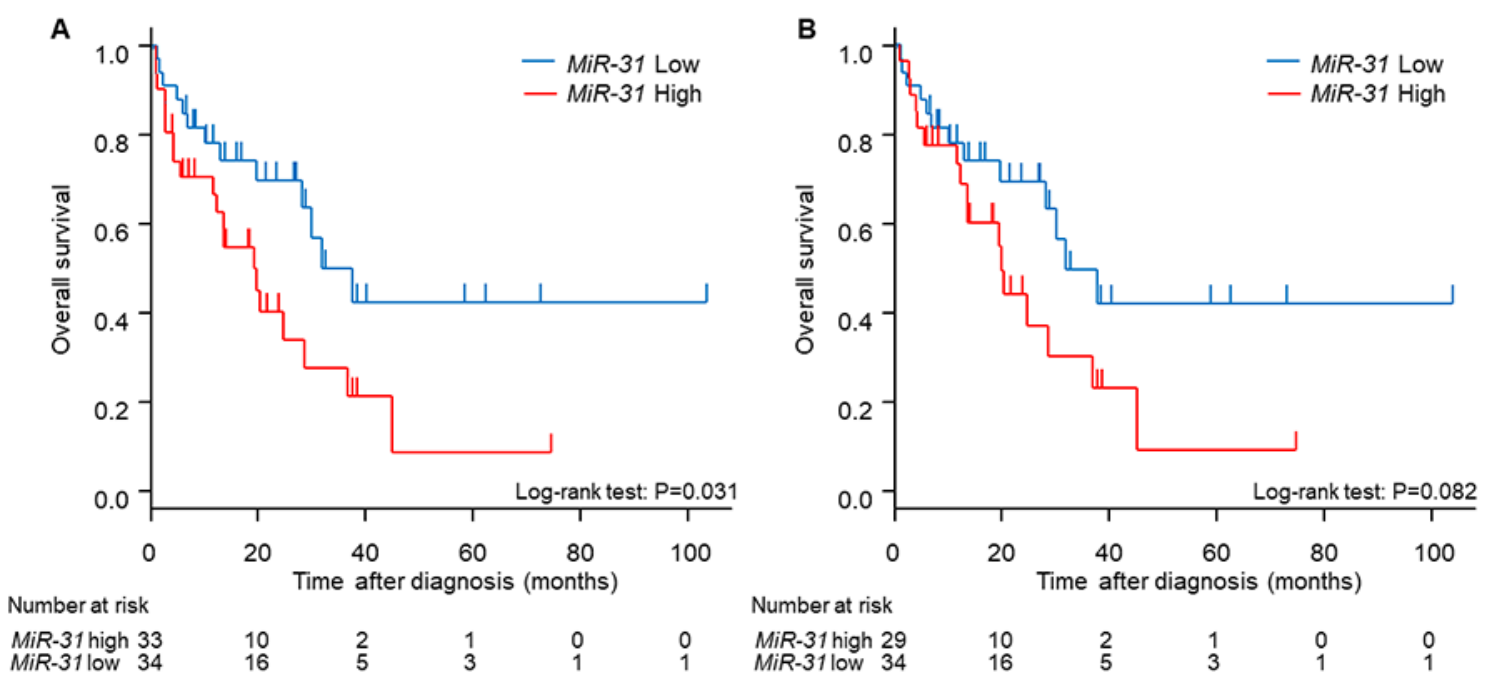

Figure 4. Kaplan-Meier curves for patients with stage IV CRC with respect to $m i R-31$ expression status analyzed by (A) including or (B) excluding patients with CRC with a BRAF mutation. miR, microRNA; KRAS, KRAS proto-oncogene, GTPase; BRAF, B-Raf proto-oncogene, serine/threonine kinase; CRC, colorectal cancer.

mutations were investigated in the present study. The results obtained from a miRNA array analysis revealed that $m i R-31$ was upregulated in $B R A F$-mutant CRC tissues compared with that in other CRC subtypes, such as $K R A S$-mutant or wild-type CRCs. The association between $m i R-31$ and $B R A F$ mutations was also confirmed in a dataset comprising information on 170 patients with CRC, retrieved from TCGA database.

In addition to its association with the $B R A F$ oncogene, miR-31 has been demonstrated to bind to the 3'-untranslated region of special AT-rich sequence-binding protein 2 (SATB2), which is a nuclear matrix-associated transcription factor and epigenetic regulator, downregulating its expression at both the mRNA and protein level (36). SATB2 was originally identified as a highly tissue-specific protein, predominantly expressed in glandular cells of the lower gastrointestinal tract, and high expression of SATB2 is an accurate prognostic marker in CRC $(37,38)$.

Another target of $m i R-31$ is RAS p21 GTPase-activating protein 1 (RASA1), which is a negative regulator of the RAS-RAF-MEK-ERK signal pathway (39). Overexpression of $m i R$-31 downregulates RASA1 protein but not RASA1 mRNA, suggesting that $m i R-31$ regulates RASA1 expression via a post-transcriptional mechanism. RASA1, with its C-terminal GAP domain, has the ability to stimulate the GTPase activity of normal RAS p21, which results in the inactivation of RAS. Thus, overexpression of $m i R-31$ in CRC may repress RASA1 and consequently upregulate the RAS pathway to promote tumor cell proliferation. Furthermore, $m i R-31$ promotes epithelial-mesenchymal transition (EMT) $(34,40)$. Cottonham et al (34) reported that CRC cell lines with elevated miR-31 expression undergo EMT (a factor associated with distant metastasis) in response to transforming growth factor (TGF)- $\beta$, without influencing the TGF- $\beta$ pathway. Meng et al (41) reported that $m i R-31$ was upregulated in lung adenocarcinoma tissues from patients with lymph node metastases, compared with those without. Additionally, in vitro functional assays demonstrated that $m i R-31$ increased cell migration, invasiveness and proliferation in an ERK1/2 signaling-dependent manner (40).
Thus, upregulation of miR-31 may enhance tumor development, as well as the malignant potential of a tumor, via inhibition of SATAB2 and RASA1, enhancement of EMT and upregulation of BRAF expression. Particularly, miR-31 upregulation is commonly observed in $B R A F$-mutant CRCs, which may enhance the downstream proteins of RAS-RAF signal cascade.

Regarding molecular targeting therapies, there are several reports indicating the influence of the expression status of $m i R-31$ (either $-3 p$ alone or both $-3 p$ and $-5 p$ ) on the sensitivity of metastatic CRC (with wild-type $R A S$ ) to anti-EGFR therapy (42-44). Patients with higher $m i R$-31 expression levels exhibited poorer outcomes during treatment with anti-EGFR therapy. As $m i R-31$ upregulates BRAF protein levels irrespective of the RAS/BRAF mutation status and inhibits RASAl mRNA (which inactivates activated RAS by stimulating GTPase) $(13,39)$, it is hypothesized that upregulation of $m i R-31$ inhibits the efficacy of anti-EGFR therapy, and acts in a manner similar to oncogenic mutations in the $R A S$ and $R A F$ genes.

To the best of our knowledge, the most effective treatment strategy for patients with stage IV CRC and BRAF mutations, which may be associated with high $m i R-31$ expression levels (13), is currently unknown. The answer may exist in a recent clinical trial for unresectable patients with $B R A F$ V600E mutant CRC, called the BEACON study (45). BRAF inhibition has been revealed to improve clinical outcomes in patients with melanoma and non-small cell lung cancer that have a BRAF V600 mutation; however, in patients with CRC, BRAF inhibition has only conferred a marginal improvement in the reduction of tumor burden (46-53). Notably, in vitro studies demonstrated that in $B R A F$ V600E-mutant CRC cells, BRAF inhibition results in the rapid feedback activation of EGFR, permitting sustained MAPK activation and continued cell proliferation; however, combined inhibition of BRAF and EGFR resulted in synergistic inhibition of tumor growth in BRAF V600E mutant CRC xenograft models $(54,55)$. Subsequent clinical studies of EGFR-targeted therapies, combined with the BRAF inhibitors vemurafenib or dabrafenib, confirmed that addition of an EGFR-targeted therapy may improve the activity of BRAF inhibition in $B R A F$ V600E-mutant CRC (55-57). In the BEACON study (45), patients 
with CRC and the BRAF V600E mutation, who had experienced treatment failure with one or two prior chemotherapy regimens, were recruited and treated with three molecular target agents, encorafenib (a BRAF inhibitor), binimetinib (a MEK inhibitor) and cetuximab (an EGFR inhibitor). In 29 patients with $B R A F$ V600E mutant tumors, the overall response rate was $48 \%$, the median progression-free survival was 8.0 months and the median OS time was 15.3 months (45). This indicates that the BRAF V600E mutation serves as a facilitator of CRC progression and therapies are required that inhibit the feedback activation of RAS-RAF signal cascade.

The present study demonstrated that high miR-31 expression was associated with $B R A F \mathrm{~V} 600 \mathrm{E}$ mutation in patients with stage IV CRC, but also indicated a poor prognosis, irrespective of $B R A F$ mutation status. Additionally, an inhibitor to $m i R-31$ may confer a clinical benefit on patients with CRC with $B R A F$ V600E mutation or high miR-31 expression levels, perhaps as part of a combination therapy alongside BRAF inhibitors, MEK inhibitors and EGFR inhibitors.

In the present study, despite the small population size, analysis of miRNA microarray data and relevant samples from TCGA database showed the reproducible result that high $m i R-31$ expression was associated with a $B R A F$ mutation and poor outcome in CRC, as demonstrated by a previous study (13). The results from the current strongly indicate that the expression level of $m i R-31$ in the primary cancer site is a promising prognostic factor for CRC regardless of the RAS/BRAF mutation profile as well as a predictive factor for anti-EGFR treatment in CRCs with wild-type $R A S / B R A F$. Thus, $m i R-31$ may represent a favorable biomarker and a promising therapeutic target in patients with CRC.

\section{Acknowledgements}

The authors would like to thank Mr. Toru Nakai and Mrs. Tae Yamanishi (Department of Gastroenterological Surgery, Okayama University Graduate School of Medicine, Dentistry and Pharmaceutical Sciences, Okayama, Japan) and Mrs. Kikue Tokuda (Clinical Oncology, Kawasaki Medical School, Okayama, Japan) for their technical assistance.

\section{Funding}

The present study was supported by The Ministry of Education, Culture, Sports, Science and Technology (MEXT)/Japan Society of the Promotion of Science (JSPS) KAKENHI (grant nos. 20590572, 25860409, 26462016, 18H03554 and 18K18464).

\section{Availability of data and materials}

The datasets generated and analyzed during the present study are available in the National Cancer Institute repository (https://www.cancer.gov/about-nci/organization/ccg/research/structural-genomics/tcga).

\section{Authors' contributions}

NK performed miRNA analysis and drafted the manuscript. FT performed TCGA data analysis. AN, YM and HT performed all
DNA extractions and $K R A S / B R A F$ mutation and MSI analyses. YU collected patient samples, clinicopathological data, assisted with data interpretation and performed statistical analyses. TF provided patient samples, clinicopathological data and designed the study. AT and YY assisted with data interpretation and revised the manuscript. TN assisted with data interpretation, designed the project, secured the funding and drafted the manuscript. All authors have read and approved the final manuscript.

\section{Ethics approval and consent to participate}

The study protocol was approved by The Ethics Committee of Okayama University Hospital and Kawasaki Medical School Hospital. All patients provided written informed consent.

\section{Patient consent for publication}

Not applicable.

\section{Competing interests}

The authors declare that they have no competing interests.

\section{References}

1. Siegel RL, Miller KD and Jemal A: Cancer statistics, 2018. CA Cancer J Clin 68: 7-30, 2018.

2. Bray F, Ferlay J, Soerjomataram I, Siegel RL, Torre LA and Jemal A: Global cancer statistics 2018: GLOBOCAN estimates of incidence and mortality worldwide for 36 cancers in 185 countries. CA Cancer J Clin 68: 394-424, 2018.

3. Yu T, Ma P, Wu D, Shu Y and Gao W: Functions and mechanisms of microRNA-31 in human cancers. Biomed Pharmacother 108: 1162-1169, 2018.

4. Kopcalic K, Petrovic N, Stanojkovic TP, Stankovic V, Bukumiric Z, Roganovic J, Malisic E and Nikitovic M: Association between miR-21/146a/155 level changes and acute genitourinary radiotoxicity in prostate cancer patients: A pilot study. Pathol Res Pract 215: 626-631, 2019.

5. Braga TV, Evangelista FCG, Gomes LC, Araujo SSDS, Carvalho MDG and Sabino AP: Evaluation of MiR-15a and MiR-16-1 as prognostic biomarkers in chronic lymphocytic leukemia. Biomed Pharmacother 92: 864-869, 2017.

6. Petrovic N: miR-21 might be involved in breast cancer promotion and invasion rather than in initial events of breast cancer development. Mol Diagn Ther 20: 97-110, 2016.

7. Toiyama Y, Takahashi M, Hur K, Nagasaka T, Tanaka K, Inoue Y, Kusunoki M, Boland CR and Goel A: Serum miR-21 as a diagnostic and prognostic biomarker in colorectal cancer. J Natl Cancer Inst 105: 849-859, 2013.

8. Hur K, Toiyama Y, Takahashi M, Balaguer F, Nagasaka T, Koike J, Hemmi H, Koi M, Boland CR and Goel A: MicroRNA-200c modulates epithelial-to-mesenchymal transition (EMT) in human colorectal cancer metastasis. Gut 62: 1315-1326, 2013

9. Fuji T, Umeda Y, Nyuya A, Taniguchi F, Kawai T, Yasui K, Toshima T, Yoshida K, Fujiwara T, Goel A and Nagasaka T: Detection of circulating microRNAs with Ago2 complexes to monitor the tumor dynamics of colorectal cancer patients during chemotherapy. Int J Cancer 144: 2169-2180, 2019.

10. Lee RC and Ambros V: An extensive class of small RNAs in caenorhabditis elegans. Science 294: 862-864, 2001.

11. Ambros V: The functions of animal microRNAs. Nature 431: 350-355, 2004.

12. Pagliuca A, Valvo C, Fabrizi E, di Martino S, Biffoni M, Runci D, Forte S, De Maria R and Ricci-Vitiani L: Analysis of the combined action of miR-143 and miR-145 on oncogenic pathways in colorectal cancer cells reveals a coordinate program of gene repression. Oncogene 32: 4806-4813, 2013.

13. Nosho K, Igarashi H, Nojima M, Ito M, Maruyama R, Yoshii S, Naito T, Sukawa Y, Mikami M, Sumioka W, et al: Association of microRNA-31 with BRAF mutation, colorectal cancer survival and serrated pathway. Carcinogenesis 35: 776-783, 2014. 
14. Samowitz WS, Sweeney C, Herrick J, Albertsen H, Levin TR, Murtaugh MA, Wolff RK and Slattery ML: Poor survival associated with the BRAF V600E mutation in microsatellite-stable colon cancers. Cancer Res 65: 6063-6069, 2005.

15. Saridaki Z, Tzardi M, Sfakianaki M, Papadaki C, Voutsina A, Kalykaki A, Messaritakis I, Mpananis K, Mavroudis D, Stathopoulos E, et al: BRAFV600E mutation analysis in patients with metastatic colorectal cancer (mCRC) in daily clinical practice: Correlations with clinical characteristics, and its impact on patients' outcome. PLoS One 8: e84604, 2013.

16. Mori $Y$, Nagasaka T, Mishima H,Umeda Y, Inada R, Kishimoto $H$, Goel A and Fujiwara T: The rare BRAF VK600-601E mutation as a possible indicator of poor prognosis in rectal carcinoma-a report of a case. BMC Med Genet 16: 1, 2015.

17. Mori Y, Nyuya A, Yasui K, Toshima T, Kawai T, Taniguchi $F$ Kimura K, Inada R, Nishizaki M, Haraga J, et al: Clinical outcomes of women with ovarian metastases of colorectal cancer treated with oophorectomy with respect to their somatic mutation profiles. Oncotarget 9: 16477-16488, 2018.

18. Morikawa T, Inada R, Nagasaka T, Mori Y, Kishimoto $H$, Kawai T, Umeda Y, Mishima H, Goel A and Fujiwara T: BRAF V600E mutation is a predictive indicator of upfront chemotherapy for stage IV colorectal cancer. Oncol Lett 15: 2195-2201, 2018.

19. Edge S, Byrd D, Compton C, Fritz A, Greene F and Trotti A: AJCC Cancer Staging Manual.https://cancerstaging.org/references-tools/ deskreferences/Documents/AJCC\%207th\%20Ed\%20Cancer\%20 Staging\%20Manual.pdf. Accessed January 7, 2013.

20. Nagasaka T, Koi M, Kloor M, Gebert J, Vilkin A, Nishida N, Shin SK, Sasamoto H, Tanaka N, Matsubara N, et al: Mutations in both KRAS and BRAF may contribute to the methylator phenotype in colon cancer. Gastroenterology 134: 1950-1960, 60.e1, 2008.

21. Goel A, Nagasaka T, Hamelin R and Boland CR: An optimized pentaplex PCR for detecting DNA mismatch repair-deficient colorectal cancers. PLoS One 5: e9393, 2010.

22. Takehara Y, Nagasaka T, Nyuya A, Haruma T, Haraga J, Mori Y, Nakamura K, Fujiwara T, Boland CR and Goel A: Accuracy of four mononucleotide-repeat markers for the identification of DNA mismatch-repair deficiency in solid tumors. J Transl Med 16: 5, 2018

23. Cancer Genome Atlas Network: Comprehensive molecular characterization of human colon and rectal cancer. Nature 487: 330-337, 2012

24. Livak KJ and Schmittgen TD: Analysis of relative gene expression data using real-time quantitative PCR and the 2(-Delta Delta C(T)) method. Methods 25: 402-408, 2001

25. Nagasaka T, Mori Y, Umeda Y and Fujiwara T: Biomarker for colorectal cancer. Nihon Rinsho 70: 802-808, 2012 (In Japanese)

26. Nikolaou S, Qiu S, Fiorentino F, Rasheed S, Tekkis P and Kontovounisios C: Systematic review of blood diagnostic markers in colorectal cancer. Tech Coloproctol 22: 481-498, 2018.

27. Zhang T, Wang Q, Zhao D, Cui Y, Cao B, Guo L and Lu SH: The oncogenetic role of microRNA-31 as a potential biomarker in oesophageal squamous cell carcinoma. Clin Sci (Lond) 121: 437-447, 2011

28. Valastyan S, Reinhardt F, Benaich N, Calogrias D, Szasz AM, Wang ZC, Brock JE, Richardson AL and Weinberg RA: A pleiotropically acting microRNA, miR-31, inhibits breast cancer metastasis. Cell 137: 1032-1046, 2009.

29. Creighton CJ, Fountain MD, Yu Z, Nagaraja AK, Zhu H, Khan M, Olokpa E, Zariff A, Gunaratne PH, Matzuk MM and Anderson ML: Molecular profiling uncovers a p53-associated role for microRNA-31 in inhibiting the proliferation of serous ovarian carcinomas and other cancers. Cancer Res 70: 1906-1915, 2010.

30. Zhang Y, Guo J, Li D, Xiao B, Miao Y, Jiang Z and Zhuo H: Down-regulation of miR-31 expression in gastric cancer tissues and its clinical significance. Med Oncol 27: 685-689, 2010

31. Schee K, Boye K, Abrahamsen TW, Fodstad O and Flatmark K: Clinical relevance of microRNA miR-21, miR-31, miR-92a, miR-101, miR-106a and miR-145 in colorectal cancer. BMC Cancer 12: 505, 2012

32. Cekaite L, Rantala JK, Bruun J, Guriby M, Agesen TH, Danielsen SA, Lind GE, Nesbakken A, Kallioniemi O, Lothe RA and Skotheim RI: MiR-9, -31, and -182 deregulation promote proliferation and tumor cell survival in colon cancer. Neoplasia 14: 868-879, 2012.

33. Chang KH, Miller N, Kheirelseid EA, Lemetre C, Ball GR, Smith MJ, Regan M, McAnena OJ and Kerin MJ: MicroRNA signature analysis in colorectal cancer: Identification of expression profiles in stage II tumors associated with aggressive disease. Int J Colorectal Dis 26: 1415-1422, 2011
34. Cottonham CL, Kaneko $\mathrm{S}$ and $\mathrm{Xu}$ L: miR-21 and miR-31 converge on TIAM1 to regulate migration and invasion of colon carcinoma cells. J Biol Chem 285: 35293-35302, 2010.

35. Wang CJ, Zhou ZG, Wang L, Yang L, Zhou B, Gu J, Chen HY and Sun XF: Clinicopathological significance of microRNA-31, -143 and -145 expression in colorectal cancer. Dis Markers 26: 27-34, 2009.

36. Mansour MA, Hyodo T, Ito S, Kurita K, Kokuryo T, Uehara K, Nagino M, Takahashi M, Hamaguchi $M$ and Senga T: SATB2 suppresses the progression of colorectal cancer cells via inactivation of MEK5/ERK5 signaling. FEBS J 282: 1394-1405, 2015.

37. Eberhard J, Gaber A, Wangefjord S, Nodin B, Uhlen M, Ericson Lindquist $\mathrm{K}$ and Jirström K: A cohort study of the prognostic and treatment predictive value of SATB2 expression in colorectal cancer. Br J Cancer 106: 931-938, 2012

38. Magnusson K, de Wit M, Brennan DJ, Johnson LB, McGee SF, Lundberg E, Naicker K, Klinger R, Kampf C, Asplund A, et al: SATB2 in combination with cytokeratin 20 identifies over $95 \%$ of all colorectal carcinomas. Am J Surg Pathol 35: 937-948, 2011

39. Sun D, Yu F, Ma Y, Zhao R, Chen X, Zhu J, Zhang CY, Chen J and Zhang J: MicroRNA-31 activates the RAS pathway and functions as an oncogenic MicroRNA in human colorectal cancer by repressing RAS p21 GTPase activating protein 1 (RASA1). J Biol Chem 288: 9508-9518, 2013.

40. Yang MH, Yu J, Chen N, Wang XY, Liu XY, Wang S and Ding YQ: Elevated microRNA-31 expression regulates colorectal cancer progression by repressing its target gene SATB2. PLoS One 8: e85353, 2013

41. Meng W, Ye Z, Cui R, Perry J, Dedousi-Huebner V, Huebner A, Wang Y, Li B, Volinia S, Nakanishi H, et al: MicroRNA-31 predicts the presence of lymph node metastases and survival in patients with lung adenocarcinoma. Clin Cancer Res 19: 5423-5433, 2013.

42. Manceau G, Imbeaud S, Thiebaut R, Liebaert F, Fontaine K, Rousseau F, Génin B, Le Corre D, Didelot A, Vincent M, et al: Hsa-miR-31-3p expression is linked to progression-free survival in patients with KRAS wild-type metastatic colorectal cancer treated with anti-EGFR therapy. Clin Cancer Res 20: 3338-3347, 2014.

43. Mosakhani N, Lahti L, Borze I, Karjalainen-Lindsberg ML, Sundström J, Ristamäki R, Osterlund P, Knuutila S and Sarhadi VK: MicroRNA profiling predicts survival in anti-EGFR treated chemorefractory metastatic colorectal cancer patients with wild-type KRAS and BRAF. Cancer Genet 205: 545-551, 2012.

44. Mlcochova J, Faltejskova-Vychytilova P, Ferracin M, Zagatti B, Radova L, Svoboda M, Nemecek R, John S, Kiss I, Vyzula R, et al: MicroRNA expression profiling identifies miR-31-5p/3p as associated with time to progression in wild-type RAS metastatic colorectal cancer treated with cetuximab. Oncotarget 6: 38695-38704, 2015.

45. Van Cutsem E, Huijberts S, Grothey A, Yaeger R, Cuyle PJ, Elez E, Fakih M, Montagut C, Peeters M, Yoshino T, et al: Binimetinib, encorafenib, and cetuximab triplet therapy for patients with BRAF V600E-mutant metastatic colorectal cancer: Safety lead-in results from the phase III BEACON colorectal cancer study. J Clin Oncol 37: 1460-1469, 2019.

46. Flaherty KT, Puzanov I, Kim KB, Ribas A, McArthur GA, Sosman JA, O'Dwyer PJ, Lee RJ, Grippo JF, Nolop K and Chapman PB: Inhibition of mutated, activated BRAF in metastatic melanoma. N Engl J Med 363: 809-819, 2010.

47. Wilmott JS, Long GV, Howle JR, Haydu LE, Sharma RN, Thompson JF, Kefford RF, Hersey P and Scolyer RA: Selective BRAF inhibitors induce marked T-cell infiltration into human metastatic melanoma. Clin Cancer Res 18: 1386-1394, 2012.

48. Dummer R, Ascierto PA, Gogas HJ, Arance A, Mandala M, Liszkay G, Garbe C, Schadendorf D, Krajsova I, Gutzmer R, et al: Overall survival in patients with BRAF-mutant melanoma receiving encorafenib plus binimetinib versus vemurafenib or encorafenib (COLUMBUS): A multicentre, open-label, randomised, phase 3 trial. Lancet Oncol 19: 1315-1327, 2018.

49. Long GV, Stroyakovskiy D, Gogas H, Levchenko E, de Braud F Larkin J, Garbe C, Jouary T, Hauschild A, Grob JJ, et al: Dabrafenib and trametinib versus dabrafenib and placebo for Val600 BRAF-mutant melanoma: A multicentre, double-blind, phase 3 randomised controlled trial. Lancet 386: 444-451, 2015.

50. Long GV, Hauschild A, Santinami M, Atkinson V, Mandala M, Chiarion-Sileni V, Larkin J, Nyakas M, Dutriaux C, Haydon A, et al: Adjuvant dabrafenib plus trametinib in stage III BRAF-mutated melanoma. N Engl J Med 377: 1813-1823, 2017.

51. Chapman PB, Hauschild A, Robert C, Haanen JB, Ascierto P, Larkin J, Dummer R, Garbe C, Testori A, Maio M, et al: Improved survival with vemurafenib in melanoma with BRAF V600E mutation. N Engl J Med 364: 2507-2516, 2011. 
52. Planchard D, Besse B, Groen HJM, Souquet PJ, Quoix E, Baik CS, Barlesi F, Kim TM, Mazieres J, Novello S, et al: Dabrafenib plus trametinib in patients with previously treated BRAF(V600E)-mutant metastatic non-small cell lung cancer: An open-label, multicentre phase 2 trial. Lancet Oncol 17: 984-993, 2016.

53. Hyman DM, Puzanov I, Subbiah V, Faris JE, Chau I, Blay JY, Wolf J, Raje NS, Diamond EL, Hollebecque A, et al: Vemurafenib in multiple nonmelanoma cancers with BRAF V600 mutations. N Engl J Med 373: 726-736, 2015.

54. Corcoran RB, Ebi H, Turke AB, Coffee EM, Nishino M, Cogdill AP, Brown RD, Della Pelle P, Dias-Santagata D, Hung KE, et al: EGFR-mediated re-activation of MAPK signaling contributes to insensitivity of BRAF mutant colorectal cancers to RAF inhibition with vemurafenib. Cancer Discov 2: 227-235, 2012.

55. Hong DS, Morris VK, El Osta B, Sorokin AV, Janku F, Fu S, Overman MJ, Piha-Paul S, Subbiah V, Kee B, et al: Phase IB study of vemurafenib in combination with irinotecan and cetuximab in patients with metastatic colorectal cancer with BRAFV600E mutation. Cancer Discov 6: 1352-1365, 2016.
56. Corcoran RB, Andre T, Atreya CE, Schellens JHM, Yoshino T, Bendell JC, Hollebecque A, McRee AJ, Siena S, Middleton G, et al: Combined BRAF, EGFR, and MEK inhibition in patients with BRAF(V600E)-mutant colorectal cancer. Cancer Discov 8: 428-443, 2018.

57. Connolly K, Brungs D, Szeto E and Epstein RJ: Anticancer activity of combination targeted therapy using cetuximab plus vemurafenib for refractory BRAF (V600E)-mutant metastatic colorectal carcinoma. Curr Oncol 21: e151-e154, 2014.

This work is licensed under a Creative Commons Attribution-NonCommercial-NoDerivatives 4.0 International (CC BY-NC-ND 4.0) License. 